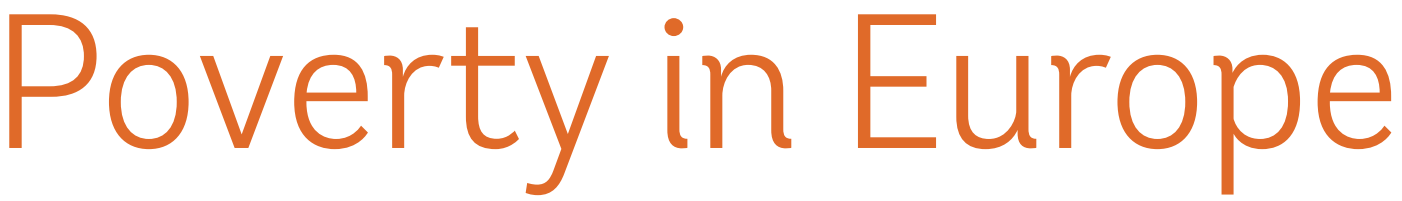

March 2016

Poverty and Equity Global

Practice

\section{Lessons Learned from Poverty Mapping in the European Union}

The Poverty Mapping in the European Union (EU) project, an initiative of the World Bank and European Commission (EC) in cooperation with EU member states, has developed a set of high-resolution poverty maps by using information from recent national population censuses and household income surveys to estimate the rates of monetary poverty for small geographic areas in EU member states. This disaggregated information can help guide allocations of EU funds to the areas in highest need as well as inform decision making and policies at the national and sub-national levels in each of the EU member states. The project succeeded in producing a large volume of high quality analytical work and made important methodological advances, but not without overcoming certain institutional challenges. This brief outlines key lessons learned from this project on working together efficiently with multiple partners.

\section{Background}

According to the latest data from Eurostat, more than 122 million people in the EUnearly 25 percent of EU citizens - are at risk of poverty or social exclusion. ${ }^{1}$ One of the five

\footnotetext{
${ }^{1}$ Eurostat Data Explorer http://ec.europa.eu/eurostat /web/income-and-living-conditions/data/main-tables Accessed January 15, 2016.
}

headline targets of the Europe 2020 strategy is to reduce the number of people living at risk of poverty or social exclusion by 20 million by the year 2020. In its 2014-2020 multiannual financial framework the EU has budgeted one trillion euros to support growth and jobs, which will contribute to reducing poverty and social exclusion. Success depends on developing the right policies and programs and targeting them effectively. Just as rates of poverty and social exclusion vary widely across EU member states, there is also a high degree of variability in living standards within EU member states. It follows that promoting convergence of living standards across the EU requires detailed knowledge of the disparities in living standards within each member state, and especially in those 
member states with high levels of poverty and social exclusion.

From 2011 to 2014, the World Bank and the EC, in cooperation with individual EU member states, have produced a set of high-resolution poverty maps. The objective is to help the EC and EU member states target funds and programs in the 2014-2020 budget cycle most efficiently to the areas in highest need. These high-resolution poverty maps combine information from recent national population censuses and EU Statistics on Income and Living Conditions (EU-SILC) household surveys ${ }^{2}$ to estimate the rates of monetary poverty for small geographic areas such as counties, districts, or municipalities. In previous years, the EC has had to rely on less detailed data and maps at the "NUTS 2" level (for example, the eight development regions in Romania) for program planning and the allocation of EU funds. ${ }^{3}$ The greater geographic disaggregation of the new poverty maps reveals which parts of these larger regions have particularly high rates of poverty risk and require greater attention for poverty reduction programs. When combined with data on population size per small area, they also provide information on where most of the poor are located. The poverty maps not only help guide allocations of EU funds, but may also be used for decision making and policies at the national and sub-national levels in each of the EU member states.

A project of this size, which involves close collaboration among the World Bank, the EC, and authorities in individual European countries, not surprisingly serves as an important learning experience for future engagement in this area.

Lesson 1: The regional development agenda can provide an entry point for small area poverty estimation

Gaining traction on the poverty agenda can be difficult in upper-middle and high income countries such as the EU member states, especially

\footnotetext{
2 For most countries the 2011 population census was used along with EU-SILC from 2011 or 2012.

3 The NUTS (Nomenclature des Unités Territoriales Statistiques) classification is a hierarchical system for sub-dividing the economic territory of the EU for the development of regional statistics, regional socioeconomic analysis, and the framing of EU regional policies. To date the NUTS 2 classification has been used for determining eligibility for aid from European Structural Funds. Below the NUTS 3 classification areas are defined according to Local Administrative Units (LAU) Most EU member states have LAU 1 and LAU 2 divisions, but some only have LAU 2.
}

among national authorities. Even though one of Europe 2020's targets is to reduce the number of people living at risk of poverty or social exclusion by 20 million, some national authorities view poverty and social exclusion as problems of developing countries, and not middle or high income countries. Other authorities recognize that poverty and social exclusion exist in their countries, but are wary of giving prominence to the issue because of its political sensitivity, especially when the project outputs will very clearly show which parts of the country are doing worse than others. This sensitivity may be heightened when the proximate initiative appears to come from Brussels and Washington rather than domestically.

However, this project has shown that it is possible to attract the necessary attention when the information is rich and presented in an accessible and appealing manner. In this instance, regional development-a very active policy area at the EU, national, and sub-national levels-proved to be a useful entry point in several countries. All central and eastern European countries have some "dead spots," where there is little economic life after communist-era industries have shut down, a situation that is often magnified by young people migrating to urban centers or other countries. Reducing spatial disparities is an active policy area for the EU and the member states, supported by the European Regional Development Fund (ERDF) and the Cohesion Fund.

Lesson 2: Building on pre-existing arrangements can help to reduce institutional barriers

The World Bank, the EC, and national authorities all share a common objective of improving the welfare of the poor, but substantial institutional barriers can make working together to achieve this objective challenging. While each organization has its own sets of rules and practices that are internally consistent, these rules and practices are often incompatible with those of external partners. However, through good-faith negotiation it has usually been possible to accommodate the concerns of all parties. Whenever possible, this project tried to build on existing precedent and to establish agreements that were sufficiently general to be effective for future projects, without reinventing the wheel. Nevertheless, the investment of time and energy required on these matters should not be underestimated.

An initial hurdle was determining an appropriate financing mechanism for the EC's support to the World Bank to engage 
in the poverty mapping initiative. As the EC was requesting a specific output it was first thought that a Reimbursable Advisory Services (RAS) agreement would be suitable. After further investigation it was determined that an RAS is not compatible with the EU's audit and verification policies. In the end it was agreed to establish a new Programmatic Trust Fund, which provided a broad and flexible basis for EC financing of World Bank knowledge and advisory services in EU member states. Creation of the trust fund was facilitated by an existing, but until then little used, trust fund framework agreement between the World Bank and the EC. The Europe 2020 Programmatic Trust Fund has served as a vehicle not only for the poverty mapping work, but also for subsequent requests from the Commission for knowledge and advisory services in support of the Europe 2020 goals.

An important lesson learned from this project is that partnering with other large and often bureaucratic institutions can involve significant transaction costs, but it can be worth the effort. When navigating conflicting institutional bureaucracies it is good to remember that someone else has probably tried something similar, and may have succeeded. Usually one may draw from one or more precedents that will work in the project's favor. It is essential to understand not only the rules each partner is following, but also which are particularly sensitive and less open to negotiation, and work within those limits. While the customization of legal agreements and working arrangements was very time consuming, it also provided an unexpected "laboratory" that enabled the team to test out practical challenges in small area poverty estimation.

Lesson 3: Strategic engagement across institutions and across countries can have great impact not only on project outcomes but also on sustainability Strategic partnerships, such as this one between the World Bank and the EC, can facilitate the development of highly technical knowledge and its direct application to policy. The high-resolution poverty maps have informed the Cohesion Policy negotiations between the EU and member states, helping to ensure that Cohesion Policy is designed to address the spatial disparities in welfare revealed by the poverty maps. The poverty maps have also been used to increase the focus of EU funds in high poverty areas and to change the investment mix to better address the underlying causes of poverty, such as access to employment, education, health services, or infrastructure.

The hands-on and intensive engagement of the EC was essential for the success of this project. The EC originally came to the World Bank because of the its extensive experience in poverty mapping and because the EC lacked the in-house resources to produce the poverty maps. However, counterparts in the EC at all levels have not only been discerning consumers of the team's work but also true partners, contributing to improvements in the team's work throughout the process, while remaining cognizant of the constraints imposed by the institutional barriers noted earlier. The exchange of ideas and information has been extremely constructive, and we expect it will continue to be so as the poverty maps are increasingly used in the EC's operations. An early sign of this is a request from the EC for additional work along these lines in 2015-2016, with an infusion of additional trust funds.

Not only is strategic engagement across institutions essential for success, but leveraging cross-country learning and resources is also fundamental. Because of higher in-country capacity and better data, middle- and high-income countries can serve as platforms for technical innovation that can then be applied to low-income countries through the development of improved tools and training. One example of this is the comprehensive registry data on income and other variables that may be linked to the EU-SILC data in several EU member states. This opened up the rare opportunity to conduct a validation study as a first step in the World Bank/EC poverty mapping project, using registry data in Denmark and Slovenia to rigorously test alternative poverty mapping methodologies.

Lesson 4: One size does not fit all Despite common EU objectives such as income convergence and common Eurostat technical standards such as the EU-SILC, a "one size fits all" approach does not work across all EU member states. The degree to which working arrangements, data access and corresponding analytical approaches, and skills transfer had to be customized in each of the countries was surprisingly varied.

Completing data access and confidentiality agreements provided an early lesson in customization. In each EU member state, the national statistical institute (NSI) has a standard data access and confidentiality agreement, but each of them have at least 
one clause that is not compatible with the World Bank's status as an international organization. Likewise, each of the NSIs found something unacceptable about the Bank's proposed agreement, which was based on the Bank's Access to Information Policy. Specific concerns about confidentiality varied from $\mathrm{NSI}$ to NSI, so that even after agreement was reached with one NSI additional modifications were needed to reach agreement with another NSI.

The working arrangement with each NSI was unique, with varying levels of NSI staff expertise and time available to work on the project, and data readiness and access. The most thorough engagements were in Estonia and Poland, where access to some parts of the data were restricted to the NSI analysts. The World Bank team sat alongside these analysts and worked together to do the small area poverty estimates from beginning to end. Interest was similarly high in Slovenia, but even though the analysis had to be done on the NSI premises for data security reasons the NSI staff could not spare time to work on the poverty mapping project because of recent staff reductions. The World Bank staff conducted the analysis in a "secure data" room, and reported on the results to the NSI staff. In Romania both NSI staff time and office space were in short supply, so the NSI management provided the World Bank team with a data disc so the team could do the analysis at World Bank offices, and report findings back to the NSI. Working arrangements in the other NSls fell somewhere in the middle of this range.

The heterogeneity across EU member states has continued through to the dissemination of the findings. For example, under the NUTS 2 classification that the EU had previously used for the allocation of EU Structural and Investment Funds, small countries such as Estonia were treated as a single entity with no regional divisions. The very detailed map of poverty rates across 132 local government units was widely publicized and the small area poverty estimates data are available for public download from the Statistics Estonia web site. In contrast, the senior management at Poland's Central Statistical Office remains skeptical about "indirect" measurement of poverty through model-based methods, and requires the World Bank to issue a disclaimer that the poverty estimates are not official Polish data.

\section{Conclusion}

The engagement of the World Bank with the $E C$ and EU member states has been successful at gaining an improved understanding of the wide variation in poverty risk across small geographic areas, both in terms of poverty levels and the underlying reasons for poverty. It has helped inform the allocation of EU funds and the design of programs. Moreover, the engagement has helped set the stage for future cooperative efforts among the various institutions, exploiting the comparative advantages of each. On an operational level, each organization has a better understanding of each other's processes and systems, and have formulated appropriate frameworks and mechanisms that facilitate rather than impede collaboration. On a more substantive level, the poverty mapping project has helped illustrate that reducing poverty remains a challenge even in the middle- and highincome countries of the EU, and has helped underscore the World Bank's role as a source of knowledge and policy advice, especially drawing from its extensive global experience. This has especially resonated in EU member states that no longer borrow from the World Bank, but are still interested in its knowledge and advisory services.

\section{About the Team}

\section{World Bank Staff and Consultants}

Kenneth Simler (Task Team Leader), Robin Audy, Alexandru Cojocaru, Céline Ferré, Indiana Fonseca, Azhar Hussain, Maureen Itepu, Sandor Karacsony, Joost de Laat, Peter Lanjouw, Katarina Mathernova, Lei Pan, Ericka Rascon, Thomas Sohnesen, Roy van der Weide, Qinghua Zhao.

\section{National Statistical Institutes \\ Estonia: Julia Aru, Kaja Sõstra \\ Hungary: Judit Dobszayné Hennel,}

Éva Ménesi, Ildikó Merkl

Latvia: Viktors Veretjanovs

Poland: Maciej Beresewicz,

Tomasz Józefowski, Tomasz Klimanek, Jacek Kowalewski, Anna Małasiewicz, Andrzej Młodak, Marcin Szymkowiak, Łukasz Wawrowski

Romania: Andreea Cambir, Nicoleta Caregea, Silvia Pisica,

Slovakia: Viera Doktoríková, Róbert Vlačuha Slovenia: Danilo Dolenc, Tomaž Smrekar 